\title{
RESEARCH PAPER \\ PREDICTION OF A DELAMINATION AREA DURING DRILLING OF CARBON COMPOSITE LAMINATES STRUCTURES
}

\author{
P. Y. Andoh ${ }^{1}$, F. Davis ${ }^{2}$, J. Antonio ${ }^{1}$ \\ ${ }^{1}$ Department of Mechanical Engineering, Faculty of Mechanical and Agricultural Engineering, \\ KNUST, Kumasi. \\ e-mail : andohp_2@yahoo.com \\ ${ }^{2}$ Department of Mechanical Engineering, North Carolina Agricultural and Technical State \\ University, Greensboro, NC 27411.
}

\begin{abstract}
The ability to non-destructively monitor and evaluate the delamination damage during a drilling operation is of interest to the scientific and the industrial community. This paper discusses the development of an empirical model that relates the feed rate to the delamination-crack area in order to enable the user determine the appropriate feed rate for an allowable degree of delamination. An acoustic emission system is used to monitor the process and supply the model with insitu parameters for instantaneous process evaluation. It is concluded that the energy response may be used to estimate the value for the drilling time before delamination occurs. The empirical model may also be used to predict the area of delamination at a given feed rate.
\end{abstract}

Keywords: Composite Laminates, Drilling, Damage, Delamination

\section{INTRODUCTION}

A quantitative analysis was performed to study the behavior of the acoustic emission signal in response to a drilling operation. Figure 1 shows a typical energy response at various drilling times (Ravishankar and Murthy, 2000). A detailed analysis of the signal characteristics reveals that the energy increases in magnitude once the delamination begins. The change in the energy is used to determine the time at onset of delamination $\left(\mathrm{t}_{0}\right)$. This parameter is critical in the sense that the delamination crack initiates at that particular time. This means that a study can then be performed to determine the time at onset of delamination and also evaluate delamination area (Krishnamoorthy et al.,
2009). This parameter may then be monitored to reduce delamination during the drilling of composite laminates. Hence more research should be performed to study the drilling time. It is also revealed that the relation between the delamination area, the feed rate and the cutting speed is given as $A_{d}=K f^{\alpha} t^{\mathrm{b}}$ (Andoh, 2005), where $\mathrm{K}, \alpha$ and $\beta$ are constants and depend on the material used. These constants need to be studied together with the drilling time at onset of delamination instead of the remaining drilling time (Andoh et al, 2010). An on-line technique may also account for the anisotropic nature of the material. AE signals are used for this purpose. There is a need to establish a quantitative relationship between the acoustic energy 


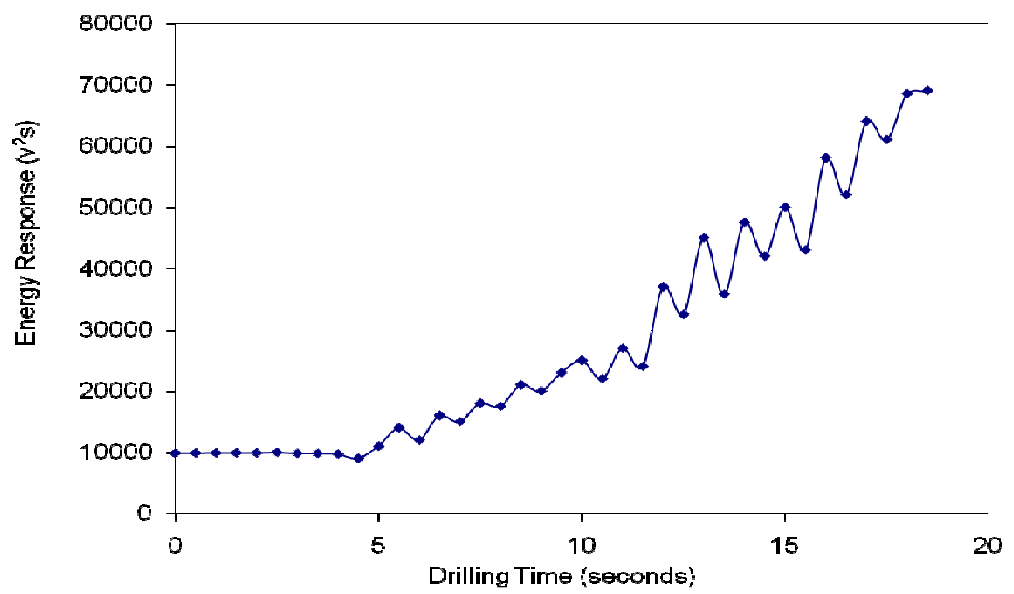

Fig. 1: Energy Response versus Drilling Time

response and the area of delamination (Andoh et al, 2007).

The mechanics of drilling composite materials depends on the fiber and matrix properties, the fiber orientation, and the fiber volume fraction inconsistencies The common defects caused by drilling of composite laminates include interply delamination, fiber pullout, and matrix cracks. These defects invariably lead to a reduction in the structural integrity of a part. The defects are presently detected after drilling by the use of various and sophisticated devices. During the drilling of composite laminates, substantial out-of-plane stresses occur at the edge of the drilled hole. This phenomenon may lead to the formation of a delamination crack. Plate delamination may occur at both the entry and exit planes, but it is generally known to be more severe at the exit plane (Mizutani et al., 2000). Figure 2 shows the delamination crack as the tool advances into the material.

Significant damage mechanisms and correlations between the average exit drill forces and the crack tip position are observed. Instantaneous forces that vary along the orientation of the cutting edges are identified in terms of their contribution to the crack propagation. Delamination cracking mode $\mathrm{I}$ is the most prominent damage mechanism (Arul et al., 2007). Hence, the study of delamination cracking is limited to this mode. The objectives of this work are to: (1) develop an empirical model to predict the area of delamination during the drilling of carbon/epoxy composite laminates; (2) determine the time of onset of delamination in order to relate the delamination area to the acoustic emission energy response. A model will then be obtained to be used to select an initial feed rate and monitored to produce a damage-free drilling process.

\section{EXPERIMENTAL METHOD}

The materials selected for the experiment were: (1) A $57 \mathrm{ply}, 0.15 \mathrm{~mm}$ (0.006 in) thick carbon/ epoxy composite panel made of Amoco T300 3K Uni-Carbon in warp with S-glass in the fill direction. This material is referred to as "Amoco T300" in the rest of the work. (2): A 26 ply, $0.36 \mathrm{~mm}$ (0.014 in) thick carbon/epoxy composite panel made of Hercules AS4 high strength, high modulus graphite fiber and a Hercules 3501 amine-cured epoxy resin matrix. This material is referred to as "Hercules AS4" in the rest of the work. The reliability and precision of the Acoustic Emission (AE) signal was first studied. This resulted in the design of a drilling fixture to eliminate the Doppler effect of the $\mathrm{AE}$ signal. In this work, $\mathrm{AE}$ tests were 
performed during each drilling operation. The schematic of the experimental set-up for the measurement of the AE signal and the drilling process is shown in Fig. 3.

The threshold frequency for the acoustic signal was set at $35 \mathrm{MHz}$ with one channel and a sample rate of $4 \mathrm{MHz}$, which is greater than ten times the natural frequency of the sensor used.
The threshold frequency was kept above the Nyquist of $16 \mathrm{MHz}$ to avoid the aliasing problem. This threshold frequency value was used to eliminate the noise obtained during the dry run (Ravishankar and Murthy, 2000). AE signal measurement parameters versus time plots were obtained for each drill test and the corresponding data were collected for subsequent analysis. The stereo microscope method is used

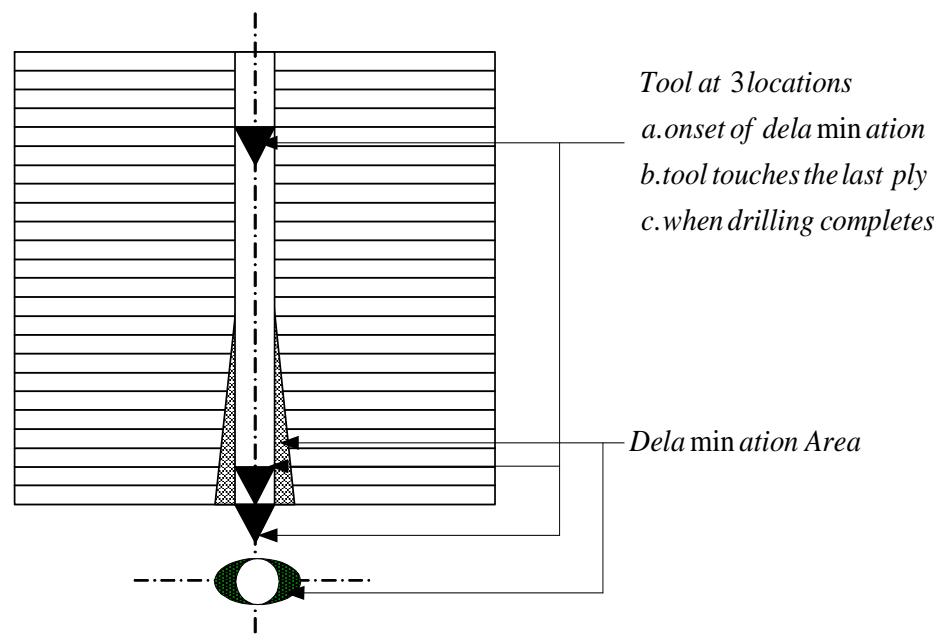

Fig. 2: Formation of Delamination Cracks

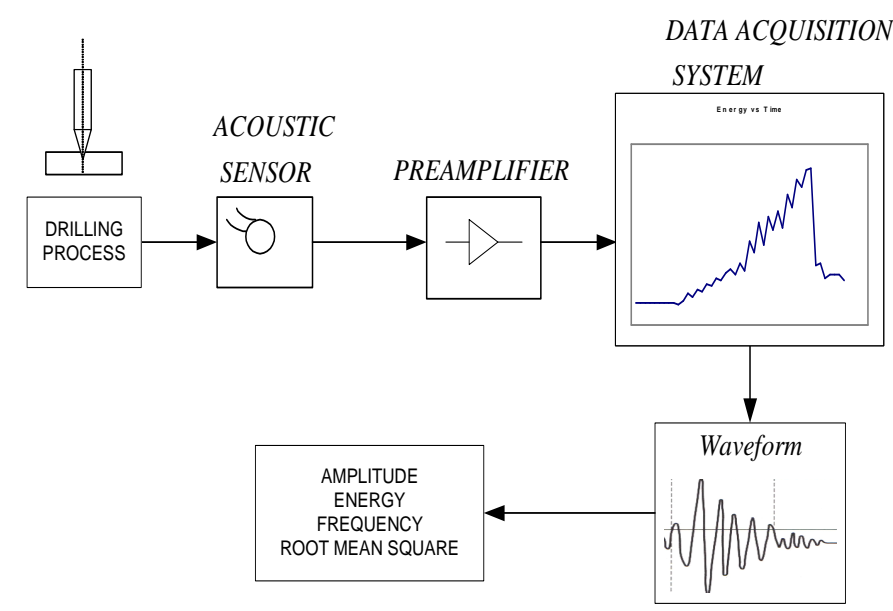

Fig. 3: Schematic Showing Experimental Set-Up 


\section{Andoh et al.}

to measure the delamination crack lengths. After each drilling process, a snap-shot by the stereo microscope is used to capture the interply delamination images. The images are processed using the Adobe Photo Shop software programme, and a sample result of the image obtained is presented in Fig. 4. The white portion represents the inter-ply delamination. An elliptical envelope is circumscribed around the damaged region. The maximum longitudinal and the transverse inter-ply delaminations are then obtained from the images by use of the size of the ellipse. growth is assumed to be linear and the line $\mathrm{A}_{\mathrm{i}} \mathrm{D}$ $(i=1,2, \ldots)$ represents the focus of the maximum crack-length at each ply-member as shown in Fig. 5. The length between position A and position $\mathrm{B}$ is termed the threshold height $\left(\mathrm{H}_{\mathrm{lp}}\right)$. At $\mathrm{C}$, the crack size is termed the longitudinal crack length $\left(a_{p}\right)$. The crack-growth angle $(\theta)$ determines the geometric relationship between $a_{p}$ and the threshold height $\mathrm{H}_{\mathrm{lp}}$. It is desirable to establish a relationship between the longitudinal delamination crack length $\left(a_{p}\right)$ and the threshold height $\left(\mathrm{H}_{\mathrm{lp}}\right)$.

From the geometry, $H_{l p}=a_{p} \tan \theta$

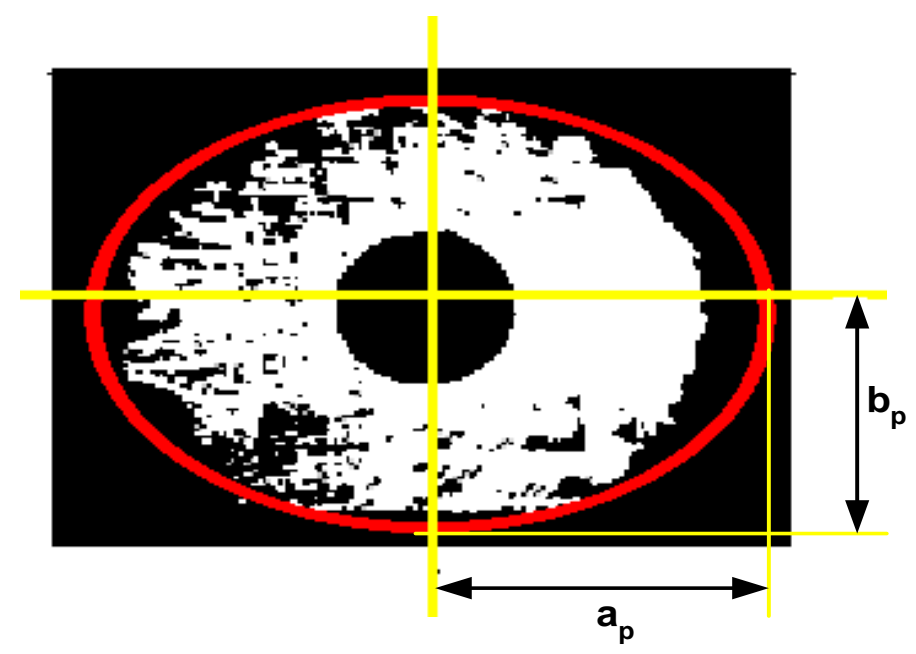

Fig. 4: Typical Image Obtained from the Stereo Microscope

\section{RESULTS AND DISCUSSION}

\section{Development of the Empirical Model}

The mechanics of drilling causes inter-ply delamination in composite laminates. A relationship is generated between the area of delamination and the drilling properties. This model is termed the empirical model. Figure 5 shows the terminology used in developing the relationship between the longitudinal crack length and the drilling time after delamination has occurred. Position A indicates the start of delamination, B indicates the piercing point, and $\mathrm{C}$ indicates the point at which drilling is complete. The crack-
Also, from drilling mechanics, $H_{l p}=f t$ where $f$ is the tool feed rate and $t$ is the remaining drilling time. Hence, combining equations 1 and $2, a_{p}=(f / \tan \theta)^{t}$

It is conceived in Fig. 5 that as the feed rate decreases, position A moves toward position B. It appears that the crack growth angle $(\theta)$ also changes. A relationship may be developed between the tangent of the crack growth angle and the feed rate. A series of tests are performed to establish this relationship. Holes are drilled at various feed rates. The stereo microscope is used to measure the longitudinal crack length 
$\left(a_{p}\right)$. For each feed rate, the threshold height $\left(\mathrm{H}_{\mathrm{lp}}\right)$ is obtained by use of the acoustic emission signals. A plot is then generated of the longitudinal crack length $\left(a_{p}\right)$ versus the feed rate and also, the threshold height $\left(\mathrm{H}_{\mathrm{lp}}\right)$ versus the feed rate for the two materials. These plots are presented in Fig. 6 and Fig. 7.

From these plots and Equations 1 and 2, the sl- ope of the crack growth angle is computed at different feed rates for the two materials. Figure 8 presents the slope of the crack growth angle versus the feed rates. The models obtained from the two plots are given as:

$\tan \theta=0.31 f^{0.09}($ for Amoco T 300)

$\tan \theta=0.32 f^{0.07}($ for Hercules AS 4)

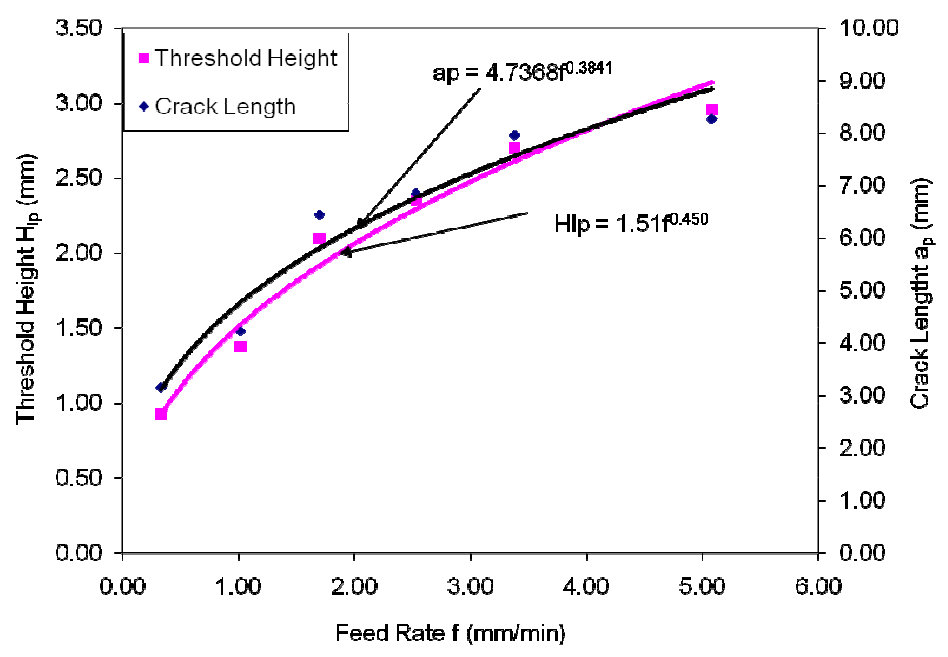

Fig. 6: Longitudinal Crack Length/Threshold Height versus Feed Rate for Amoco T300

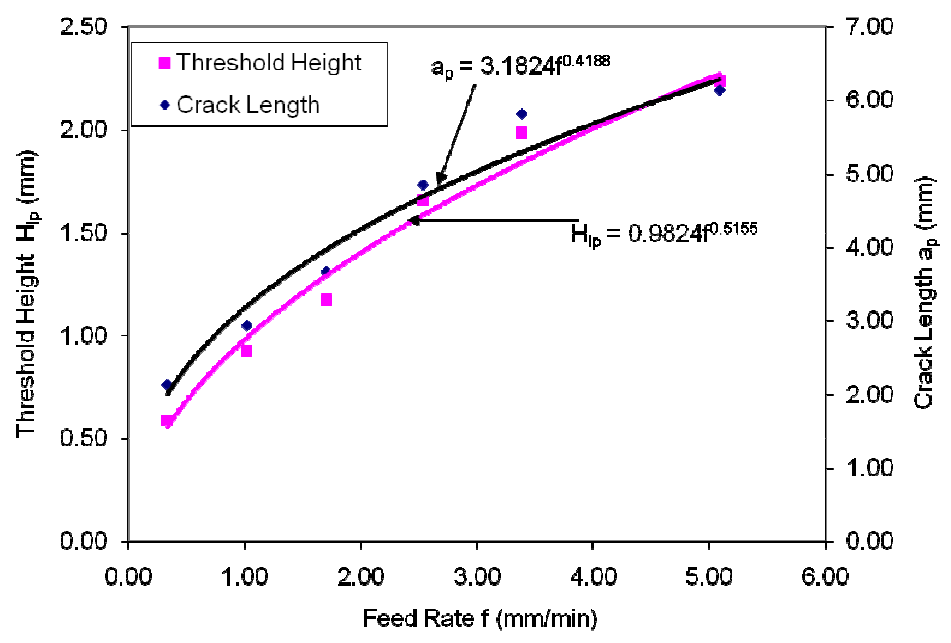

Fig. 7: Longitudinal Crack Length/Threshold Height versus Feed Rate for Hercules AS4 


\section{Andoh et al.}

Combining Equations 3 and 4, quantitative relationships between the longitudinal crack length and the remaining drilling time for the two materials are as follows:

$a_{p}=3.23 f^{0.91} t \quad($ for Amoco $T 300)$

$a_{p}=3.13 f^{0.93} t \quad($ for Hercules AS 4)

These models predict the crack length in the longitudinal direction only Delamination may occur in both the longitudinal and the transverse directions. Hence, a relationship must be developed in the transverse direction. This will enable us to develop a relationship between the area of delamination and the remaining drilling time after delamination has occurred.

A model may also be developed for the transverse crack length versus the feed rate and drilling time using the same approach as in the pre- vious section. The model may be expressed as:

$$
b_{p}=(f / \tan \lambda) t
$$

$$
\text { and } \tan \lambda=H_{l p} / b_{p}
$$

where $\lambda$ is the inclined transverse crack growth angle.

Holes are drilled at a cutting speed of 1600 $\mathrm{mm} / \mathrm{min}$, a tool diameter of $6 \mathrm{~mm}$, and at various feed rates. The stereo microscope is used to measure the transverse crack length $\left(b_{p}\right)$ and the $\mathrm{AE}$ signal is used to extract the threshold height. A plot is generated of the transverse crack length $\left(b_{p}\right)$ versus the feed rate and also of the threshold height $\left(\mathrm{H}_{\mathrm{lp}}\right)$ versus feed rates. These are illustrated in Fig. 9 and Fig. 10.

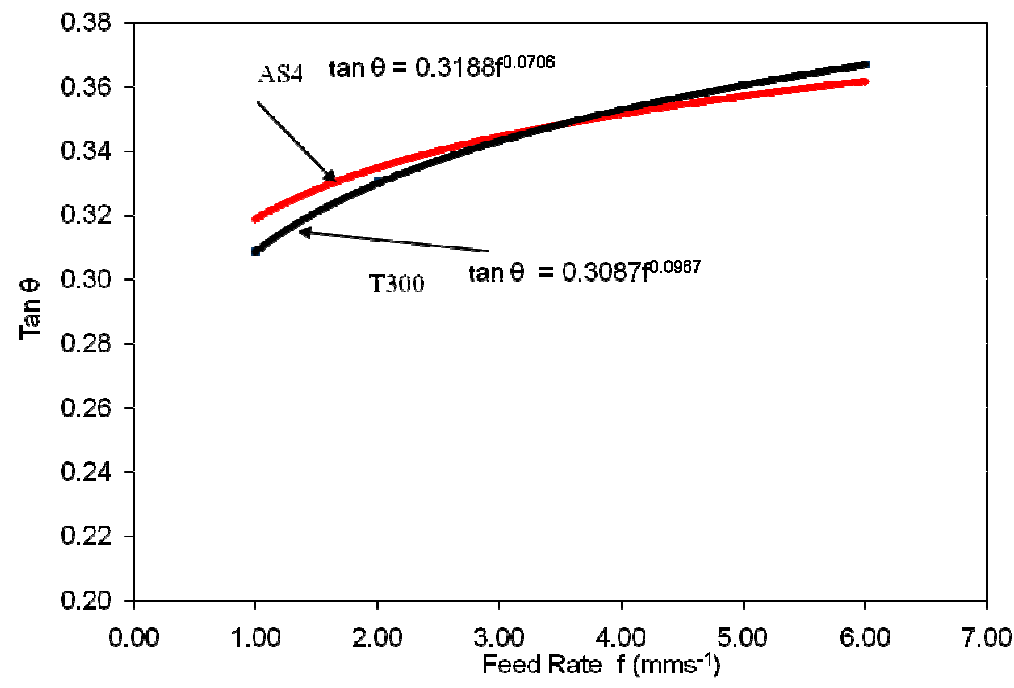

Fig. 8: Tangents of the Inclined Crack Growth Angle ( $\theta)$ and the Feed Rates 


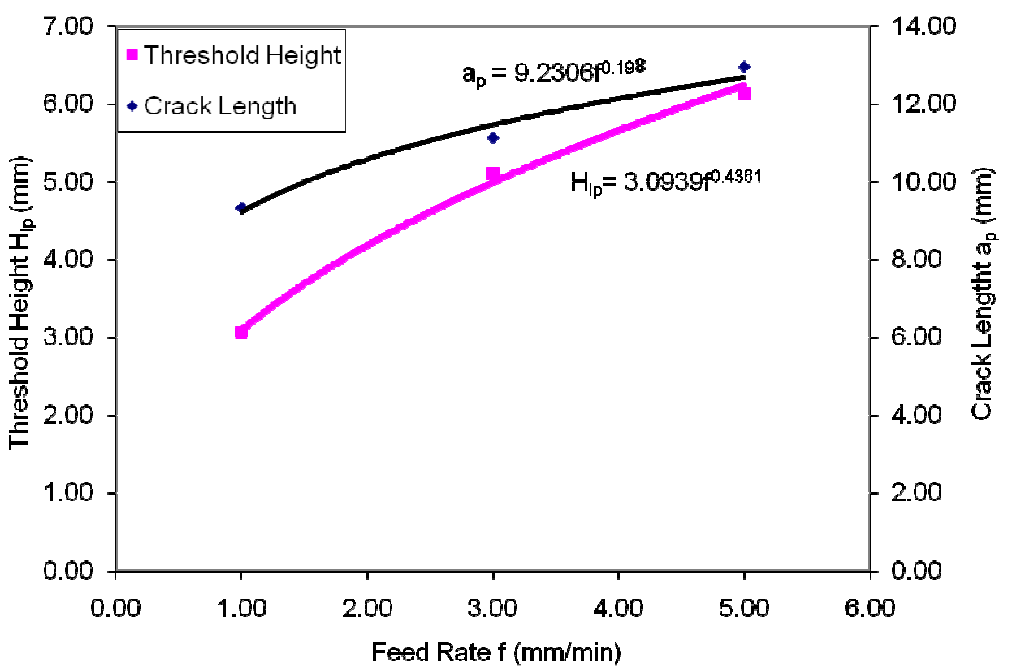

Fig. 9: Transverse Crack Length/Threshold Height versus Feed Rate for Amoco T300

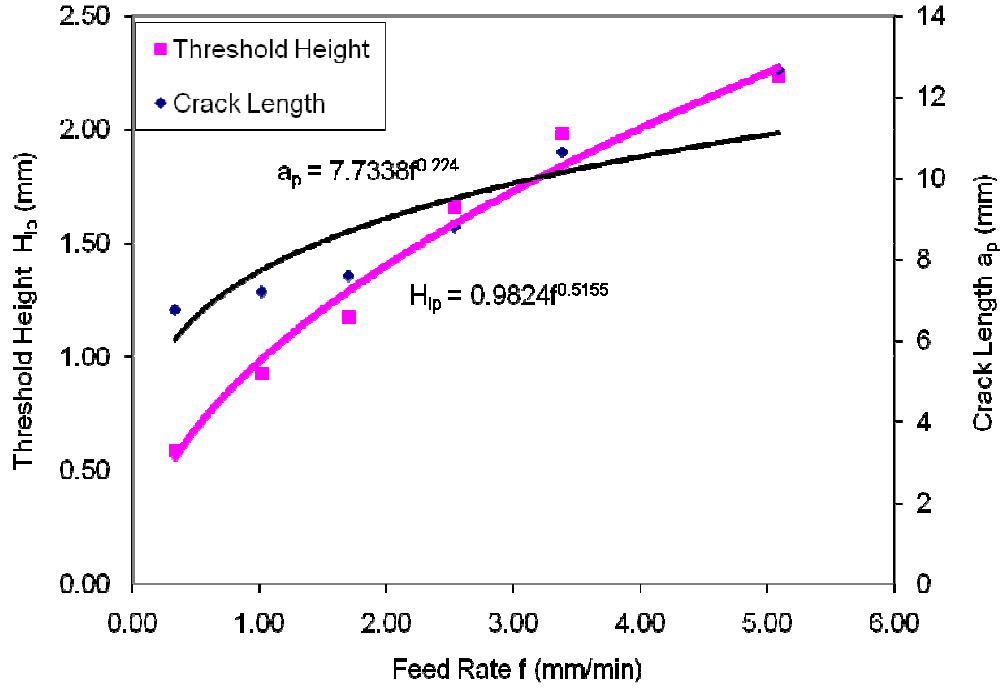

Fig. 10: Transverse Crack Length/Threshold Height versus Feed Rate for Hercules AS4 


\section{Andoh et al.}

From these plots, and Equations 6 and 7, the slopes of the crack growth angle are computed at different feed rates. Plots are established of the tangents of the angle versus the feed rates for the two materials. These plots are presented in Fig. 11.

The models obtained from the two plots are given as:

$\tan \lambda=0.3351 f^{0.24}($ for Amoco $T 300)$

$\tan \lambda=0.1179 f^{0.20}($ for Hercules AS 4)

Combining Equations 6 and 8, quantitative relationships between the transverse crack length and the remaining drilling time for the two materials are as follows:

$b_{p}=2.98 f^{0.76} t($ for Amoco $T 300)$

$b_{p}=2.39 f^{0.80} t($ for Hercules AS 4)

A relationship may now be developed for the delamination area and the drilling time that remains after delamination is initiated. Three delamination situations may occur during the drilling of composite laminates. Fig. 12 illustrates these situations.

Figure 12 depicts three situations: For case 1, there is no net delamination since both the longitudinal and the transverse crack lengths are smaller than the tool radius; for case 2 , there is delamination in the longitudinal direction with the crack length larger than the tool radius and; for case 3 , there is delamination in both the longitudinal and transverse directions with both crack lengths larger than the tool radius. Because of these possible delamination situations, there is a need to determine the area of delamination. The delamination is determined to be elliptical in shape. Hence, the area of delamination may be found from the parameters of an ellipse. The longitudinal crack length may be represented by half of the major axis $\left(a_{p}\right)$ and the transverse crack crack length may be represented by half of the minor axis $\left(b_{p}\right)$. Therefore,

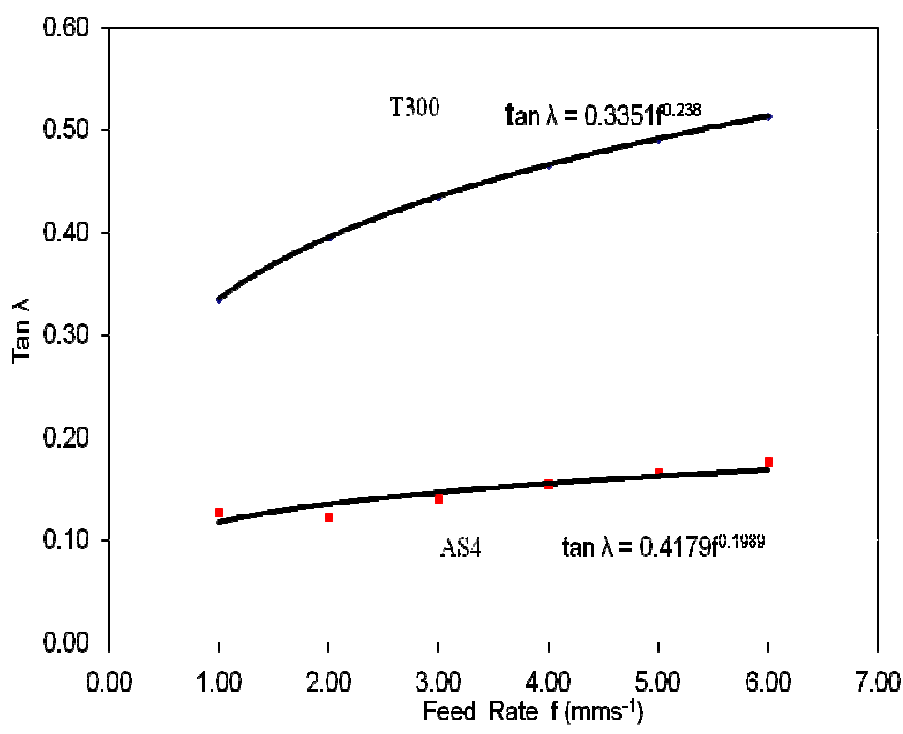

Fig. 11: Tangents of the Crack Growth Angle $(\lambda)$ and the Feed Rates 
Case 1: No Delamination

Case 2: Delamination in longitudinal direction

Case 3: Delamination in both Longitudinal and Transverse Directions

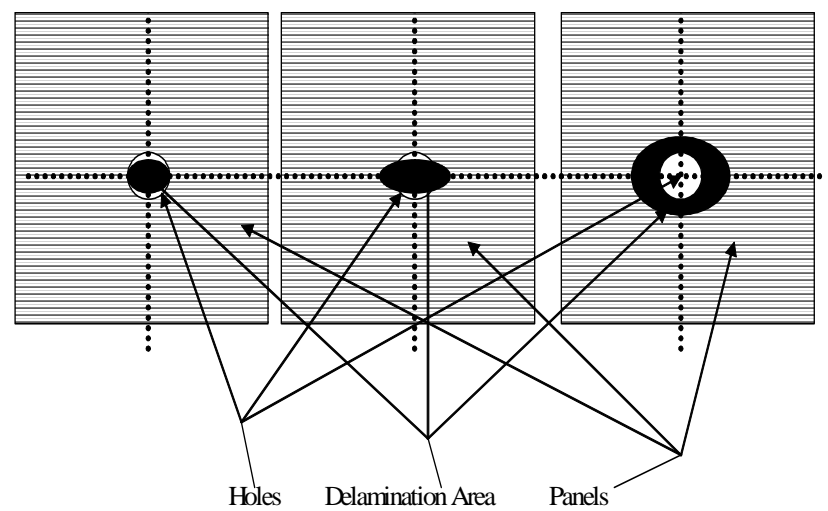

Fig. 12: Relationship between Tool Size and Crack Dimensions

the area of delamination $\left(A_{d}\right)$ is given by

$A_{d}=\pi a_{p} b_{p}$

Combining Equations 5, 9 and 10, the model of the area of delamination and drilling time at different feed rates is given as:

$A_{d}=30.24 f^{1.67} t^{2}($ for Amoco $T 300)$

$A_{d}=23.50 f^{1.73} t^{2}($ for Hercules $A S 4)$

This model is an empirical model since it depends on the mechanics of the drilling process. The model may be used to predict the delamination area at any feed rate if the remaining drilling time $(t)$ is known. It can be seen that keeping the delamination area constant, a relation can be developed between the feed rate and the remaining drilling time. Setting the area of the delamination $A_{d}$ to be equal to the area of the drill bit, several combinations of feed rate, $f$ and remaining drilling time $t$ can be obtained using equations (11a) and (11b). These sets of values may then be used to plot graphs to relate the feed rate to the remaining drilling time. Fig- ure 13 shows the plots relating the feed rate to the remaining drilling time.

Figure 13 shows that the feed rate is inversely proportional to the remaining drilling time. It also known from equations $11 \mathrm{a}$ and $11 \mathrm{~b}$ that as the remaining drilling time decreases, the exit delamination crack becomes small. Figure 2 shows that the entry delamination crack is removed as the tool advances into the material. Therefore, the exit delamination is more critical as compared to the entry delamination crack. This means that it is advisable to delay the onset of delamination to be able to produce less delamination crack at the exit. This can be achieved by using a higher feed rate for the first few plies and low feed rate for the remaining plies during the drilling process. It is also necessary to study the behavior of the drilling time at onset of delamination and also monitor it during the drilling process.

\section{Determination of Drilling Time at Onset of Delamination}

The AE signal is used to determine the drilling time when delamination begins $\left(t_{0}\right)$. The remai- 
ning drilling time, $t$, is subsequently calculated. Figure 1 shows a typical energy response at various drilling times. Using the recorded values for the energy response, the change in energy responses is computed between each two successive time intervals. A plot is generated from these values and a typical plot is presented in Fig. 14.
Figure 14 shows that the change in energy $(\Delta \mathrm{E})$ starts becoming significant when $t$ is $4.5 \mathrm{~s}$. Thus, $t_{o}=4.5 \mathrm{~s}$. The total drilling time is given as:

$$
t_{T}=\frac{H+\Delta H}{f}
$$

where $H$ is the thickness of the material and $\Delta H$

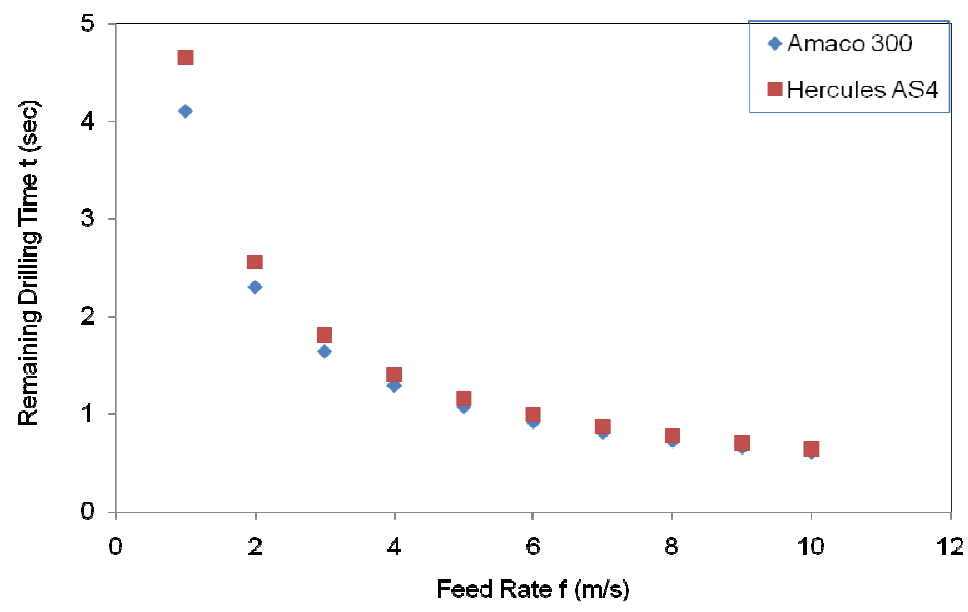

Fig. 13: Feed Rate versus Remaining Time

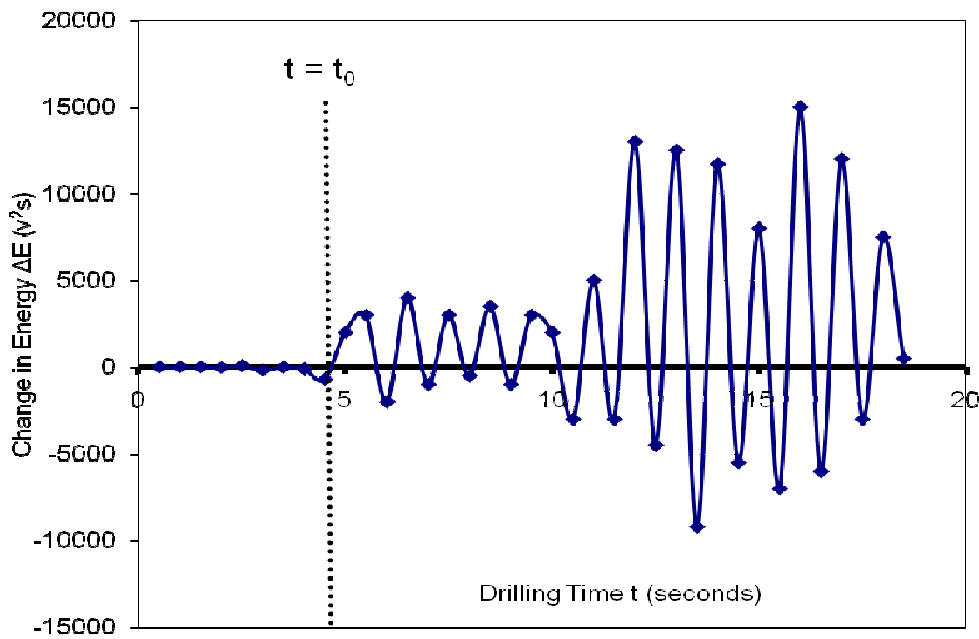

Fig. 14: Change in Energy Response versus Drilling Time 
is the height of the tip of the drilling tool. $\Delta H=$ $0.3 d$ for a conventional drill. Knowing $t_{0}$ and $t_{T}$, the remaining drilling time $(\mathrm{t})$ can be determined as:

$$
t=t_{T}-t_{0}=\frac{H+0.3 d}{f}-t_{0}
$$

Equation 11 can then be written as:

$A_{d}=\alpha f^{\beta}\left(\frac{H+0.3 d}{f}-t_{0}\right)^{2}$

where $\alpha$ and $\beta$ are constants that depends on the drilling conditions and the type of material used. Equation 14 can be used to monitor the delamination area during drilling of composite laminates. Therefore, there is the need to establish a relation between delamination area and the acoustic energy response since the measurement of the delamination area is off-line method.

\section{A Model between Energy Response and the Delamination Area}

The acoustic energy responses are recorded during the drilling process and the corresponding longitudinal and transverse crack lengths are measured at each drilling stage. The area of delamination is found to be elliptical. Thus the area of delamination may then be computed from the two crack lengths using the formula:

$$
A_{d}=\pi a_{p} b_{p}
$$

where $a_{p}$ and $b_{p}$ are the two crack lengths. The responses and the delamination parameters at different feed rates for the two materials used were also obtained. Let $E_{n}$ be the energy response obtained at time $\mathrm{t}$ and $E_{0}$ the energy obtained when there is no delamination. The change in energy response $\Delta E_{n}$ is given as:

$$
\Delta E_{n}=E_{n}-E_{0}
$$

A quantitative relationship was then established between the area of delamination and the acoustic energy response using the computed values obtained from the experimental measured or recorded data. Plots were then generated to relate the area of delamination to the energy response for the different feed rates. These plots are illustrated in Fig. 15. The models obtained from these plots show that there is a linear relationship between the change in energy response and the delamination area that may generally be expressed as:

$$
\Delta E_{n}=a_{0} A_{d}-a_{1}
$$

where $a_{0}$ and $a_{l}$ are constants and are functions of the feed rate and depend on the characteristics of the material. The constants $a_{0}$ and $a_{l}$ need to be studied with regard to the cutting parameters and the characteristics of the material. At the onset of delamination, the change in energy response is denoted by $E_{0}$, thus the general equation can be expressed as:

$$
E(t)=E_{0}+\Delta E_{n}=E_{0}+a_{0} A_{d}-a_{1}
$$

Combining equations 14 and 18, the energy response can be related with the feedrate and the drilling time at onset of delamination. This can then be expressed as:

$$
E(t)=E_{0}+a_{0} A_{d}-a_{1}=E_{0}+a_{o}\left[\alpha f^{\beta}\left(\frac{H+3 d}{f}-t_{0}\right)\right]+a_{1}
$$

To select an initial feed rate to produce the minimum delamination area, the total energy response should be set to be equal to the energy response at onset of delamination. The initial feed rate may then be computed from the formula:

$$
f=\left[\frac{1}{\alpha(H+3 d)}\left(\frac{a_{1}}{a_{0}}+t_{0}\right)\right]^{\frac{1}{\beta-1}}
$$




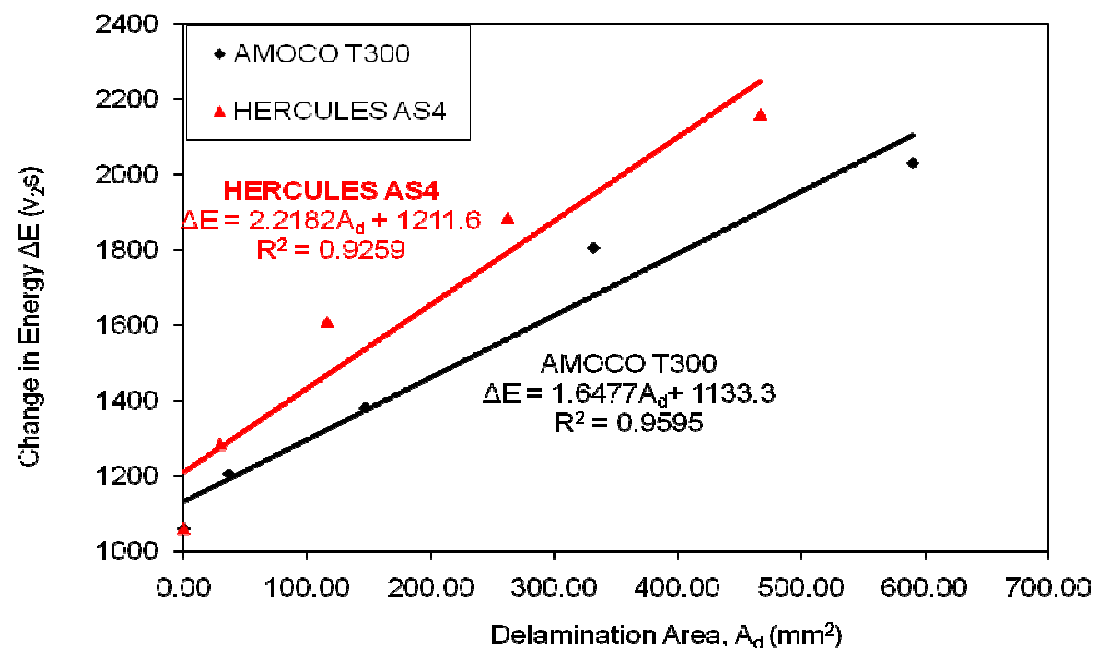

Fig. 15: Change in Acoustic Energy and Area of Delamination for Feed Rate of $1 \mathrm{mms}^{-1}$

The values of energy response $\left(E_{0}\right)$ and drilling time $\left(t_{0}\right)$ at onset of delamination can be obtained from the experimental results. The values of $\alpha$ and $\beta$, are then extracted from the plots relating the delamination area to the feed rate and the remaining drilling time (equation 11) for the two materials. Similarly the values of $a_{0}$ and $a_{l}$ are then extracted from the plots relating the delamination area to the change in energy response (equation 18) for the two materials.

\section{Selection and Monitoring of the Feed Rate}

First, the thickness of the material is divided into sections as shown in Fig. 2. Each part is drilled at a cutting speed of $1000 \mathrm{~mm} / \mathrm{min}$ and a drill diameter of $6.4 \mathrm{~mm}$. The feed rate needs to be computed and monitored at each depth in the material during the drilling process in order to maintain the energy response at onset of delamination $E_{0}$. The following steps may then be used to obtain the initial feed rate. From these experimental results, the drilling time and the energy response at onset of delamination were obtained which falls within experimental error. The results are presented in Table 1. Figure 16 shows the steps used to compute for the initial feed rate and also monitor the drilling time at onset of delamination to control the recorded energy response below the threshold value.

Using equation 20 and the results obtained from experiments as presented in Table 2, the initial feed rates computed for the two materials are $2.46 \mathrm{mms}^{-1}$ and $2.47 \mathrm{mms}^{-1}$. Therefore, a feed rate of $3 \mathrm{mms}^{-1}$ was selected for the drilling. The initial cutting conditions used to study the monitoring of the drilling time at onset of delamination and monitor the energy response at onset of delamination are presented in Table 2 . The energy responses are recorded for both the monitored and the unmonitored experiments. The results for the energy responses are plotted against the ply number and presented in Fig. 17. Only one of the unmonitored signal remains above the threshold value during the entire process while the monitored signal remains under the threshold value. This means that the model developed to be used to compute for the initial feed rate is effective even if the process is not monitored. Hence a second material which is the Hercules AS4 was also used to verify the effectiveness of the model. The 
Table 1: The Model Constants

\begin{tabular}{cccccc}
\hline & T300 & AS4 & & T300 & AS4 \\
\hline $\mathrm{a}_{0}$ & 1203.10 & 1531.30 & $\alpha$ & 30.34 & 23.50 \\
$\mathrm{a}_{1}$ & 13.68 & 20.35 & $\beta$ & 1.67 & 1.73 \\
$\mathrm{E}_{0}$ & 19961.26 & 19230.19 & $\mathrm{H}$ & $8.80 \mathrm{~mm}$ & $8.80 \mathrm{~mm}$ \\
$\mathrm{t}_{0}$ & 1.74 & 1.65 & $\mathrm{~d}$ & $6.40 \mathrm{~mm}$ & $6.40 \mathrm{~mm}$ \\
\hline
\end{tabular}

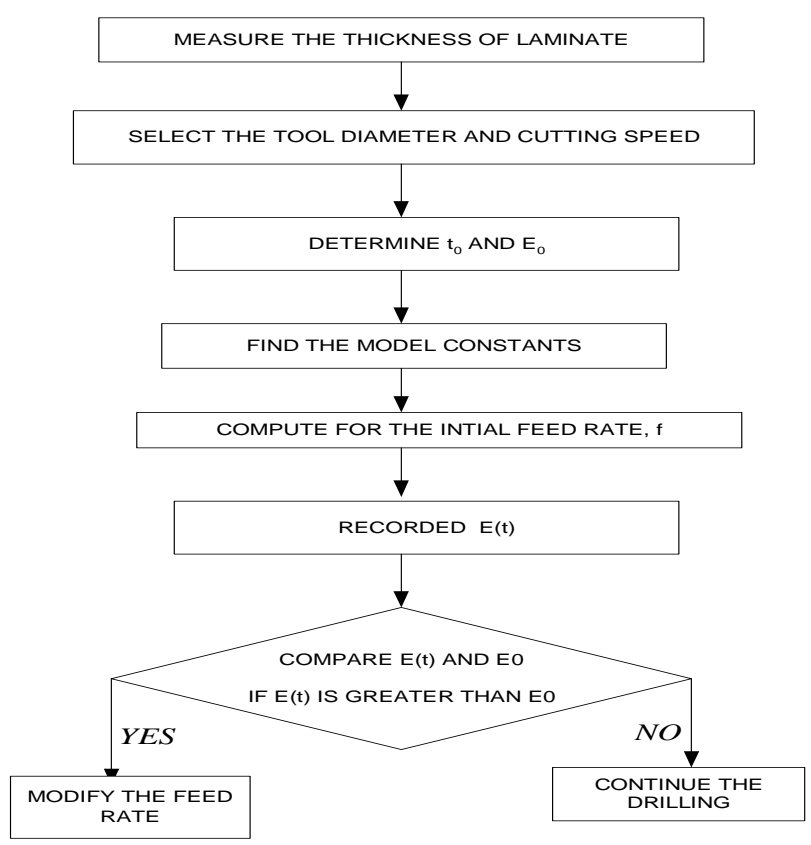

Fig. 16: Implementation of the Selection Monitor of the Drilling Process

Table 2: Initial Cutting Conditions

\begin{tabular}{cc}
\hline Cutting Condition & Values \\
\hline Feed rate & $3 \mathrm{mms}^{-1}$ \\
Cutting speed & $1000 \mathrm{mms}^{-1}$ \\
Drill diameter & $6.4 \mathrm{~mm}$ \\
\hline
\end{tabular}




\section{Andoh et al.}

results for the energy responses are plotted against the ply number and presented in Fig. 18. It seems that the results obtained for the Hercules AS4 is similar to those of the Amoco T300.
This means that the model can be used to compute for the initial feed rate that will result in a minimum delamination area which may be removed as the tool advances into the material.

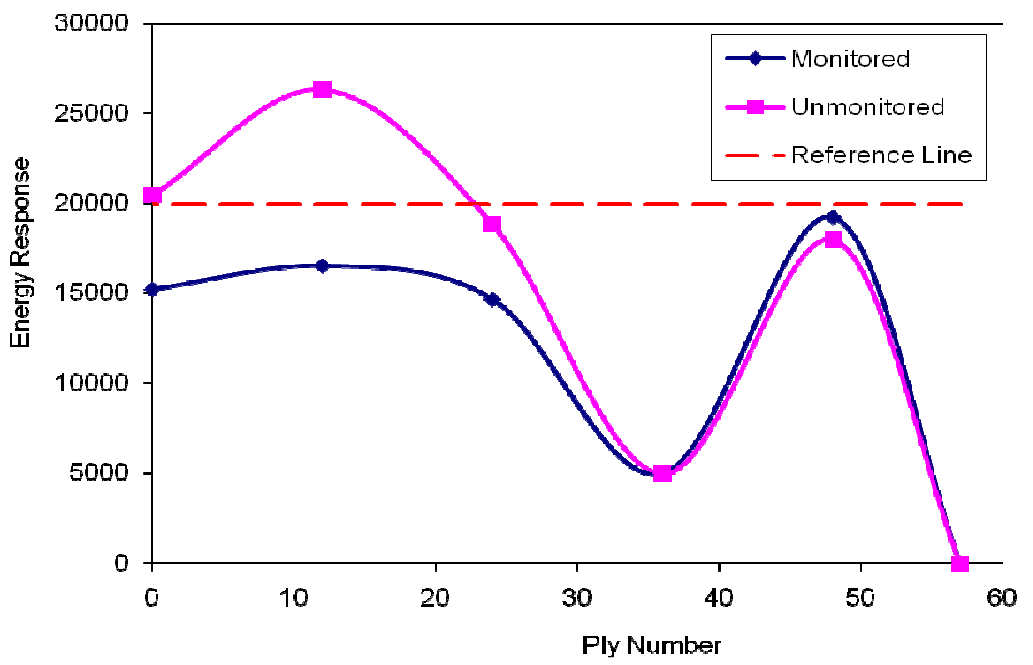

Fig. 17: Energy Response versus Ply Number @ speed of 1000 mm/min for Amoco T300

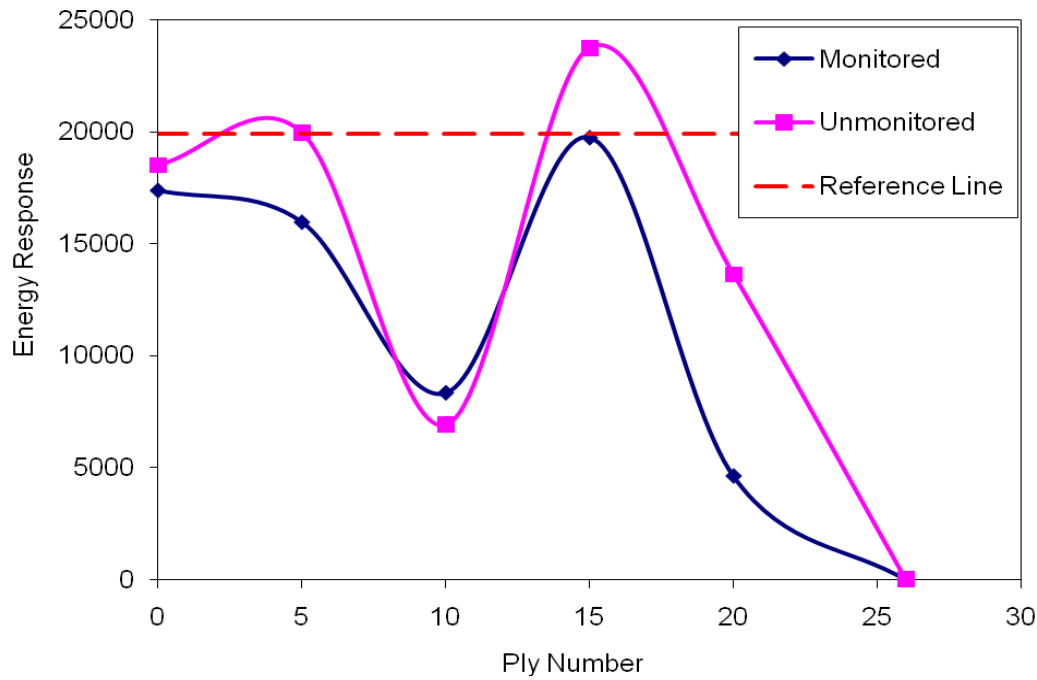

Fig. 18: Energy Response versus Ply Number @ speed of 1000 mm/min for Hercules AS4 


\section{CONCLUSION}

An acoustic emission signal has been used to predict and monitor the delamination damages by numerous investigators. Owing to its success, the method is gradually becoming a standard inspection technique and inherent inprocess prediction and monitoring capability. This paper focuses on the development of an empirical model to relate the feed rate to the delamination-crack area in order to enable the user determine the appropriate feed rate for an allowable degree of delamination. It is concluded that the energy response may be used to monitor the onset of delamination. The changes in the acoustic energy signals are used to determine the time at which delamination begins. This allows for the evaluation of the final crack area. The empirical model may also be used to predict the area of delamination at a given feed rate.

\section{REFERENCES}

Andoh, P. Y., Davis, F. and Owusu-Ofori, S. (2010). "Development of A Control Strategy for Monitoring the Delaminating Damage in Drilling of Carbon Composite Laminates" Journal of Science and Technology, vol. 30(3):109-118.

Andoh, P. Y., Davis, F. and Antonio, J. (2007). "Effects of Cutting Parameters on Acoustic Emission Signal Response during Drilling of Laminated Composites using Factorial
Design Method", Journal of Science and Technology, 3 (2):98-106.

Andoh, P. Y. (2005). "Monitoring and Control of Delamination in the Drilling of Carbon/Epoxy Composite Laminates", PhD Dissertation, North Carolina A \& T State University, Greensboro.

Arul, S., Vijayaraghavan, L. and Malhotra, S. K. (2007). "Online monitoring of acoustic emission for quality control in drilling of polymeric composites", Journal of Materials Processing Technology, 185 (1-3): 184190.

Krishnamoorthy, A., Rajendra Boopathy, S. and Palanikumar, K. (2009). "Delamination during Drilling in Composite Laminates", Transactions of the ASME, Journal of Engineering for Industry, 112: 236-239.

Mizutani, Y., N'agashima, K., Takemoto, M. and Ono, K. (2000). "Fracture mechanism characterization of cross-ply carbon-fiber composites using acoustic emission analysis", NDT \&. E International, 33: 101-110.

Ravishankar, S. R. and Murthy, C. R. L. (2000). "Characteristics of AE signals obtained during" drilling of composite laminates", NDT \& E International, 33: 341348. 